IdeAs

Idées d'Amériques

5 | 2015

Crise ou transformations du monde du travail dans les Amériques

\title{
Antônio Torres au Salon du livre de Paris, 20-23 mars 2015
}

Rita Olivieri-Godet

\section{(2) OpenEdition \\ Journals}

Édition électronique

URL : https://journals.openedition.org/ideas/973

DOI : $10.4000 /$ ideas. 973

ISSN : 1950-5701

Éditeur

Institut des Amériques

Référence électronique

Rita Olivieri-Godet, « Antônio Torres au Salon du livre de Paris, 20-23 mars 2015 », IdeAs [En ligne], 5 |

2015, mis en ligne le 05 juin 2015, consulté le 20 octobre 2022. URL : http://journals.openedition.org/ ideas/973; DOI : https://doi.org/10.4000/ideas.973

Ce document a été généré automatiquement le 20 octobre 2022

\section{(c)}

Creative Commons - Attribution - Pas d'Utilisation Commerciale - Pas de Modification 4.0 International - CC BY-NC-ND 4.0

https://creativecommons.org/licenses/by-nc-nd/4.0/ 


\title{
Antônio Torres au Salon du livre de Paris, 20-23 mars 2015
}

\author{
Rita Olivieri-Godet
}

1 Antônio Torres (1940, Junco-Bahia) est un des écrivains invités du Salon du livre dont les romans représentent la diversité thématique et formelle de la production littéraire brésilienne contemporaine. Auteur d'une dizaine de romans dont quatre traduits en français (Cette terre; Chien et loup ; Un taxi pour Vienne d'Autriche et Mon cher cannibale), il a reçu plusieurs prix littéraires.

2 Le succès obtenu avec la publication de Cette terre au Brésil, en 1976 - roman aujourd'hui traduit dans plusieurs langues - consacre définitivement l'écrivain, élu à l'Académie Brésilienne des Lettres en 2013. Cette terre met en scène la migration tragique des paysans du Nordeste vers São Paulo, la capitale économique du Brésil. Le récit explore les deux facettes d'un même pays - le Brésil rural et le Brésil urbain. Un vrai chef-d'œuvre qui renouvelle la tradition du récit régionaliste aussi bien par ses innovations formelles que par l'approche de la thématique sociale qui n'abandonne pas pour autant une perspective dense et intériorisée du drame de la sécheresse. Ce roman s'ouvre également à une réflexion sur le déracinement tragique auquel est condamnée une partie considérable de la population dans le contexte actuel de la mondialisation.

3 Une autre facette de l'œuvre d'Antônio Torres explore les rapports entre fiction et histoire et inaugure un dialogue avec l'Histoire de France. Deux de ses romans empruntent des éléments à des événements communs à l'histoire française et à l'histoire brésilienne : O nobre sequestrador (2003) et Meu querido canibal (2000) (Mon cher cannibale), qui, selon l'auteur lui-même, est un "récit historique écrit d'une manière romancée ». Après le Salon du livre de Paris, l'auteur s'est également rendu à Rennes, le 25 mars, pour participer à une table ronde autour de son œuvre et dédicacer son roman. Pour un avant-goût de ce texte romanesque, je vous propose la lecture de la postface que j'ai écrite, dont le texte est repris ci-dessous.

4 Antônio Torres, Mon cher cannibale [Meu querido canibal, Brazil, RECORD], Paris, Editions Petra, Collection Voix d'Ailleurs, 2015 [2000], traduit du portugais du Brésil par Dominique Stoenesco. Postface de Rita Olivieri-Godet. 
5 Le public francophone a déjà pu explorer l'univers de l'écrivain brésilien Antônio Torres dans ses romans Cette terre (éd. Métallié, 2002), Chien et loup (éd. Phébus, 2000) et Un taxi pour Vienne d'Autriche (éd. Gallimard, 1992). Mobilités sociales, mémoire familiale et sociale, violence urbaine. Cette diversité thématique et stylistique de l'un des auteurs les plus originaux de la littérature brésilienne contemporaine est doublée d'une capacité à tisser des histoires fortes et surprenantes qui nous dévoilent un monde dans lequel nous vivons en aveugles.

6 Cette traduction de Dominique Stoenesco du roman Meu Querido Canibal (éd. Record, 2000), récompensé par un prix littéraire au Brésil en 2001, nous donne le plaisir de découvrir un autre versant de son œuvre. Mon cher cannibale est le premier roman d'Antônio Torres basé sur des événements communs à l'histoire française et à l'histoire brésilienne, le second étant $O$ Nobre Sequestrador (éd. Record, 2003). Mon cher cannibale met en scène l'Indien Cunhambebe de la nation tupinamba - qui habitait la région de la baie de Guanabara lors de l'invasion française de Rio de Janeiro, en 1555 - dans le cadre du projet de construction d'une France Antarctique, sous le commandement de Nicolas Durand de Villegagnon ; O Nobre Sequestrador s'inspire de la biographie de René DuguayTrouin, corsaire du roi Louis XIV, qui, en 1711, assiégea pendant 50 jours la ville de Rio de Janeiro. Ces œuvres, qui travaillent les rapports entre littérature et histoire, croisent des regards entre le Vieux Monde et le Nouveau Monde tout en interrogeant le sens d'une telle rencontre.

7 La trame originale de Mon cher cannibale se nourrit de la confrontation entre le modèle culturel occidental et les cultures amérindiennes. Publié en 2000, date symbolique au Brésil avec la commémoration des 500 ans de sa "découverte ", ce roman d'Antônio Torres contribue à la réinterprétation du parcours historique de la Nation brésilienne, en questionnant le passé, en créant des passerelles avec le présent et en s'interrogeant sur son avenir, dans un monde de plus en plus globalisé. "Mon livre est une cannibalisation de l'histoire et de la littérature ", affirme Antônio Torres qui exprime de façon concise la facture complexe de cette œuvre ${ }^{1}$. Son amplitude temporelle permet de révéler les conséquences dramatiques de l'ethnocentrisme et des formes de violence qui traversent le passé et le présent de la nation brésilienne. Ce roman est également une sorte de récit-témoignage sur le temps présent. Centrée sur la construction imaginaire de l'Amérindien comme figure de l'Autre, l'œuvre affiche sa solidarité envers la résistance engagée par les peuples amérindiens, mais elle ne se limite pas à cette fonction contestataire. Elle extrait sa force du lien établi entre la production de signes et la visée critique qu'elle prétend instaurer, comme l'illustre la partialité assumée par le narrateur dans la construction du personnage de Cunhambebe. En explorant de manière radicale les frontières entre littérature et histoire, elle s'éloigne $\mathrm{du}$ modèle du roman historique traditionnel par le biais du questionnement des conventions de fictionnalité et de véracité.

8 Dans le texte hybride de Mon cher cannibale, Antônio Torres met en œuvre un intense processus intertextuel, dans le sillage de l'irrévérence anthropophage des modernistes brésiliens. Il remet en question la frontière des genres en incorporant de multiples configurations discursives telles que : le récit historique, la chronique, le récit mythique, le poème, les paroles de chansons, le langage publicitaire, avec lesquelles il dialogue pour produire sa fiction. Outre Cunhambebe, l'autre héros anthropophage présent dans le texte est le narrateur lui-même qui présente sa version des faits, dans un langage courant et ludique, qui détone au milieu des conventions et normes 
adoptées par le «discours historique monumental». Le récit dynamique, d'une délicieuse bonne humeur, qui use et abuse du potentiel subversif de l'ironie, invite le lecteur à participer au jeu de la création. Le ton irrévérencieux et souvent humoristique contraste avec le caractère dramatique du thème. L'apparente simplicité de la prose résulte, en vérité, d'un travail habile et sophistiqué d'articulation d'éléments multiples qui participent à la construction narrative.

9 L'œuvre est structurée autour de trois grandes parties marquées par des temporalités diverses. Dans la première partie, «Le Cannibale et les Chrétiens ", l'action se focalise sur la dispute entre Portugais et Français pour la conquête d'un territoire qui correspondrait aujourd'hui, en partie, à la ville de Rio de Janeiro. Elle met en relief les conséquences de cette guerre pour les peuples amérindiens. En évoquant le processus de déterritorialisation des Indiens qui habitaient cette région, dans le contexte historique colonial axé sur l'épisode de l'invasion française de Rio de Janeiro, au XVI ème siècle, l'auteur discute la formation d'une image virtuelle des Amérindiens véhiculée par l'Imaginaire de l'Autre - l'Européen. Antônio Torres établit un dialogue intense avec les récits de voyage d'André Thevet, Jean de Léry et Hans Staden, entre autres. La seconde partie, "Au commencement Dieu s'appelait Monan », nous transporte dans le temps mythique des récits sur la création du monde, en confrontant le livre de la Genèse à la mythologie des Tupinambas.

11 La troisième partie, "Voyage à Angra dos Reis ", situe l'action « à l'aube du sixième siècle après la Découverte du Brésil » et transporte abruptement le lecteur dans la contemporanéité en établissant un parallèle entre les formes actuelles de violence et celles qui ont conduit au massacre des Amérindiens.

12 Par son titre, Mon cher cannibale annonce l'engagement affectif du narrateur vis-à-vis de son personnage. Sa version de l'histoire s'assume pleinement comme un exercice d'héroïsation des Tupinambas, et en particulier de Cunhambebe. Tout au long du récit, le narrateur indique les limites de la reconstruction des faits historiques. Il met en doute la véracité du discours hégémonique occidental, responsable de la confiscation de l'histoire des peuples amérindiens. Profondément bakhtinien, le narrateur imite tous les types de discours et en invente d'autres, destinés à compenser les lacunes d'une Histoire qui n'est pas intéressée par des « histoires d'Indiens ». Le récit résulte à la fois du matériel dont dispose le narrateur-auteur-historien-anthropologue-sociologue, fruit d'un vaste travail de recherche, et de son habileté à créer et imaginer des anecdotes qui articulent le réel et l'imaginaire, comme il est de rigueur dans la fiction. La problématisation de la narration historique, caractéristique de la " métafiction historiographique ", va de pair avec une conscience autoréflexive et parodique. La fictionnalisation de l'histoire, telle qu'elle apparaît dans le roman, permet la réécriture et la re-sémantisation de faits qui configurent l'histoire du Brésil, en réintégrant le point de vue des Amérindiens dans le concert des discours.

Mon cher cannibale se positionne en faveur d'un projet utopique ouvert à l'interaction des diversités culturelles et perméable à la rencontre. Le croisement des différentes voix, ainsi que le style parodique et ironique du texte, empêchent d'attribuer à ce récit le statut de nouveau « récit-maître ». C'est là que réside la grande originalité du roman, qui puise son caractère subversif dans cette mobilité du discours contestataire. Il s'inscrit dans une mer d'histoires, dont il n'est qu'une des versions possibles. L'expression exubérante, le ton provocateur, la vision décapante de l'histoire proposée 
par Antônio Torres interpellent le lecteur au-delà de l'intérêt thématique évident de Mon cher cannibale pour le public français.

\section{NOTES}

1. Antônio Torres, «A consacração dos dois Brasis ", Zéro Hora, Porto Alegre, Segundo Caderno/ Jornada Literária, 29 août 200.

\section{AUTEUR}

\section{RITA OLIVIERI-GODET}

Rita Olivieri-Godet nasceu na Bahia. Graduada em Letras (português-francês) pela Universidade Federal da Bahia, com doutorado em Teoria literária e literatura comparada pela Universidade de São Paulo e pós-doutorado em literatura comparada em Paris X, foi professora titular de teoria literária na Universidade Estadual de Feira de Santana-Bahia (1980-1997) e Maître de conférences de literatura brasileira em Paris 8 (1998-2003). Atualmente é professora titular de literatura brasileira da Université Rennes 2 e membro do Institut Universitaire de France (promoção 2013). Autora de vários artigos e obras sobre a literatura brasileira contemporânea e as relações literárias interamericanas dentre as quais se destacam as publicações recentes: L'altérité amérindienne dans la fiction contemporaine des Amériques. Brésil, Argentine, Québec (Québec: PUL, 2015); Viva o povo brasileiro. A ficção de uma nação plural (São Paulo: é Realizações, 2014); Jorge Amado em letras e cores (ensaios de Olivieri-Godet; desenhos de Juraci Dórea, Feira de SantanaBahia, UEFS Editora, 2014). 